\title{
Indigenous firefighters: The important role of the Pemón indigenous brigades in the construction of intercultural fire management in Canaima National Park, Venezuela
}

\author{
Millán, Adriana ${ }^{1,2}$ e Bilbao, Bibiana ${ }^{2}$ \\ 1 Centro de Investigación y Transferencia (UNRaf-CONICET), Rafaela, Argentina, \\ adrianamillan@gmail.com. \\ 2 Departamento de estudios Ambientales, Universidad Simón Bolívar, Caracas, Venezuela, \\ bbilbao@usb.ve.
}

\begin{abstract}
The Vegetation Wildfire Control Program (VWP) of the hydroelectric company CORPOELEC-EDELCA in Canaima National Park (CNP), has more than 35 years of continuous operation, undertaken by local native Pemón indigenous brigade members. Historically, the policies of the VWCP have aimed at fighting and suppressing fire, to protect the forests of the upper Caroní river basin (an area of 18,000 km2 that includes Gran Sabana Sector of CNP). This basin supports the hydroelectric Guri dam complex that provides $70 \%$ of the country's energy demand. Only $13 \%$ of the $2500-3000$ fires that occur in the region each year are extinguished, despite constant and costly suppression efforts undertaken by these brigades. These suppressing fire policies, dictated by the senior management of CORPOELEC-EDELCA, have generated conflicts with Pemón indigenous communities. For the Indigenous peoples, fire is a central element of their cultural worldview used in their daily subsistence activities (sowing, hunting, fire prevention and protection of their forests). Increases in frequency and severity of vegetation fires due to climate change demand a rapid transformation of these suppression paradigms towards participatory and intercultural fire policies. The role of Pemón brigades is fundamental for the development of innovative institutions-communities' cooperation methodologies that promote spaces for co-management of fire in indigenous territories. This work summarizes the scope of workshops and interviews focused on the consultation and exploration of scenarios to integrate indigenous ancestral knowledge of fire management and the technical capabilities and experience of the VWCP. Participants agreed to a new model of integral fire management based on the inclusion of indigenous communities within participatory schemes. They pointed out that knowledge and practical exchange activities with the communities are beneficial for establishing direct contact with various indigenous groups (elders, captains, teachers, youngsters), understand and value indigenous cultural heritage (framed within the prevention program), and establishing cooperation agreements. Additionally, indigenous firefighters were recognized as critical stakeholders for the promotion and preservation of local wisdom, in a context where indigenous knowledge is going through a process of intense acculturation.
\end{abstract}

Keywords: Indigenous knowledge, fire, indigenous firefighter, integral fire management, Vegetation Wildfire Control Program, Canaima National Park. 